\title{
ANÁUSE ESTRUTURAL E QUADRO TECTÔNICO EVOLUTIVO DA BORDA LESTE DO ESPINHAÇO SETENTRIONAL - SUDOESTE DO ESTADO DA BAHIA
}

\author{
GÉLBIO MF. ROCHA*
}

\begin{abstract}
STRUCTURAL ANALYSIS AND TECTONIC EVOLUTION OF THE ESPINHACO SETENTRIONAL IN THE SOUTHWESTERN REGION OF THE STATE OF BAHIA. Important concentrations of manganesiferous mineralizations are found hi Southwest of Bahia State disposed in two distinct stratigraphic levels. The earlier one is associated to Licinio de Almeida Complex of Archean/Lower Proterozoic, while the later one is referred to the Borda Leste Depositional Sequence of Middle Proterozoic age. The most important structural features seen in the studied area are: stratigraphical reversal with reversed layers, tight isoclinal folds verging westwards, axial plane slaty cleavage, ductile shear zone, mineral stretching lineation, asymmetric folds verging eastwards and axial plane crenulation cleavage. The structural elements show varied intensity and interference relations suggesting deformational pulses in sequence and not homogeneous. The ordertoexplain the tectonical framework of the region, the polyphase model has been chosen, where the regionally printed deformation results from processes occurring in two large tectonical periods: Pre-Espinhaco and Espinhaço. Pre-Espinhaço tectonics evolved in Transamazonian Cycle (nearly $2.0 \mathrm{Ga}$ ) and/or it had taken place in previous cycles and it has only affected Licinio de Almeida Complex rocks in one phase (Do), at least Espinhaco tectonics came into play,most probably, at the end of Brasiliano Cycle(about 0.6 $\mathrm{Ga}$ ) and it also affected die Middle Proterozoic Cover (Espinhaco and Borda Leste depositional sequences). This tectonics has originated three sets of structures printed upon the rocks as phase or subphase recordings $\left(D_{1}, D_{2}\right.$ e $\left.D_{3}\right)$. which are caused by local or regional changes in the application of the tectonic stress.
\end{abstract}

Keywords: Espinhaço Setentrional, Bahia southwestern, structural analysis, tectonic evolution.

\begin{abstract}
RESUMO No sudoeste do Estado da Bahia, encontram-se concentrações importantes de mineralizações manganesfferas distribuídas em dois níveis estratigráficos distintos. $O$ mais antigo está associado ao Complexo Licinio de Almeida do Arqueano/Proterozóico Inferior e, o mais novo, à Seqüência Deposicional Borda Leste do Proterozóico Médio. As feicões estruturais mais importantes encontradas na área estudada são: inversão estratigráfica com inversão de camadas, dobras isoclinais apertadas com vergência para oeste, clivagem ardosiana de plano axial, zonas de cisalhamento dúctil, lineação de estiramento mineral, dobras assimétricas com vergência para leste, clivagẹm de crenulação de plano axial. Os elementos estruturais mostram intensidade variada e relações de interferência que sugerem pulsos de deformação seqüenciados e não-homogêneos. Para explicar o arcabouço tectônico da região, optouse pelo modelo poUfásico, no qual a deformação impressa regionalmente é resultante de processos ocorridos em dois grandes períodos tectôm'cos:Pré-Espinhaco e Espinhaço. A Tectônk`Pré-Espinhaco ocorreu no Ciclo Transamazônico (aproximadamente 2,0 Ga) e/ou em ciclos anteriores e afetou somente a rochas do Complexo Licinio de Almeida em pelo menos uma fase (Dn). A Tectônica Espinhaço se processou, mais provavelmente, no final do Ciclo Brasiliano (aproximadamente 0,6 Ga) e afetou também a cobertura do Proterozóico Médio (Seqüências Deposicionais Espinhaço e Borda Leste). Nesta tectônica, originaram-se três conjuntos de estruturas, impressas nas rochas como registros de fases ou subfases $\left(\mathrm{D}_{,}, \mathrm{D}_{2}, \mathrm{D}_{3}\right)$, decorrentes de mudanças locais ou regionais na distribuição do esforço tectônico.
\end{abstract}

Palavras-chaves: Espinhaço Setentrional, sudoeste da Bahia, análise estrutural, evolução tectônica.

INTRODUÇÃO Ocorrências de manganês são conhecidas no sudoeste da Bahia desde 1948 e, a partir de 1955, quando se iniciaram os trabalhos de prospecção e lavra, a região tem sido o mais importante centro produtor de manganês da Bahia. As reservas totais do distrito são estimadas, segundo dados oficiais, em tomo de 2.000 .000 de toneladas de minério. Em virtude desta potencialidade econômica, a região tem sido objeto de importantes trabalhos de pesquisa básica, destacando-se os trabalhos de Portela et al. (1976), Stein et al. (1976), Moraes (1980) e Souza (1987).

O ambiente geológico regional do Sudoeste da Bahia é constituído, simplificadamente, pelo embasamento gnáissicogranítico (Complexos Metamórncos e Metamórficos-Migmatfticos de Mascarenhas et al. 1979) de idade arqueana/ proterozóica Inferior e pelos metassedimentos do Supergropo Espinhaço (Proterozóico Médio) que afloram na serra homônima. O embasamento possui composição variada e contém faixas intercaladas de formações feníferas, ferromanganesíferas, quartzitos, mármores, cálcio-silicáticas, anfibolitos, xistos etc., metamorfizadas na fácies anfibolito. Já, o Supergrupo Espinhaço é formado por um pacote de rochas metassedimentares metamorfizadas na fácies xisto verde, sendo constituído predominantemente por filitos granatíferos, formações ferro-manganesíferas, conglomerados, quartzitos e filitos grafitosos.
Portela et al. (1976), Stein et al. (1976) e Moraes (1980) defendem a aplicação do modelo clássico de evolução arqueana baseada no conceito de greenstone belt às rochas do embasamento. Segundo esses autores, o Complexo Metamórfico, portador da mineralização de manganês, representa uma sequiência vulcano-sedimentar de caráter básico a ultrabásico. Esta afirmação, contestada por Souza (1987) e aceita por Inda \& Barbosa (1978), Mascarenhas et al. (1979) e Sá (1983), é de aplicação bastante duvidosa, já que não são reconhecidas, na região, rochas vulcânicas (máficas ou félsicas) com algum tipo de associação com os metassedimentos mineralizados em manganês.

A subdivisão estratigráfica do Supergrupo Espinhaço, na área em questão, é bastante confusa. Os trabalhos anteriores deram muita ênfase a critérios puramente tectônicos (Moraes 1980) ou puramente litoestratigráficos (Portela et al. 1976, Moutinho da Costa \& Silva 1980), gerando uma profusão enorme de nomes de difícil aplicação prática. Algumas vezes, uma mesma unidade, repetida por dobramentos regionais, recebeu posição estratigráfica e denominação distintas. Como conseqüência, a estratigrafia proposta para o Supergrupo Espinhaço apresenta contradições intransponíveis para o entendimento do ambiente geológico local.

\footnotetext{
* Superintendência de Geologia e Recursos Minerais, Centro Administrativo da Bahia, 4ª Avenida, 430, CEP 41206-000, FAX (071) 231-5655, Salvador, Bahia, Brasil
} 
O quadro estrutural encontrado nos trabalhos anteriores, apesar de apresentar contradições em muitos pontos, enfatiza a presença de dobras isoclinais e faixas de cisalhamento como sendo as feições estruturais mais evidentes. Portela et al. (1976), por exemplo, defendem um modelo a partir de anticlinórios e sinclinórios de grande amplitude e dobras menores variando de abertas a isoclinais. Esses autores afirmam que falhas inversas e de empurrão são comuns nas bordas de zonas geoanticlinais, sendo que o empurrão principal, observado na borda leste da Serra do Espinhaço, entre Licínio de Almeida e Boquira, colocou as rochas do embasamento por sobre as rochas do Espinhaço, gerando foliações regionais com direções ortogonais ao sentido do movimento. Moraes (1980) inicia a análise estrutural da área utilizando-se do conceito de fases de deformação. Uma primeira fase, constituída por dobramentos simétricos a assimétricos com eixo N-S, sendo afetada por uma segunda fase, representada por movimento de blocos transcorrente sinistrai, associada a dobras de arrasto com eixo de caimento forte. Apesar desse autor não discutir a existência de falhas de empurrão na área, os contatos litológicos mostrados nos mapas e perfis de seu trabalho são sistematicamente delimitados por falhas inversas. Mais recentemente, Souza (1987) esquematiza um modelo estrutural subdividindo-o em três fases de dobramento: a primeira fase é isoclinal com eixo N-S, associada a evento tarditectônico de empurrão, e as outras duas fases, também com eixo N-S, seriam representadas por dobras variando de apertadas a suaves com desenvolvimento de crenulação (fase 3). Apesar do conhecimento estrutural ter avançado com os modelos propostos, fica ainda muito dificil entender a geometria estrutural da área estudada, principalmente quando se elege o minério ou outra camada qualquer como guia estratigráflco.

ÁREA ESTUDADA A área escolhida para o desenvolvimento da análise estrutural está mostrada na figura 1. Nessa área, estão concentradas as principais minas e ocorrências de manganês do sudoeste da Bahia e foi objeto de trabalhos sistemáticos realizados pela Superintendência de Geologia e Recursos Minerais (Rocha 1991), os quais consistiram, basica- mente, de mapeamento geoló gico na escala 1.40.000, tratamento de dados aerogeofisicos (Garrido 1984) e levantamento magnetométrico terrestre em trends previamente determinados, elegendo camadas magnetizadas do embasamento como guia estratigráfico.

No estudo da cobertura sedimentar (Supergrupo Espinhaço), onde as relações primárias ainda estão bem preservadas, utilizou-se o conceito de sistemas deposicionais. Este conceito e método para análise de bacias sedimentares foi desenvolvido principalmente na região do Golfo do México (Fisher \& McGowen 1969, Hsher \& Brown 1972, Brown \& Fisher 1977), como uma solução para analisar e interpretar grandes espessuras de sedimentos. $O$ enfoque adotado, portanto, foi o de identificar na região estudada, os principais sistemas deposicionais como definido por Hsher \& McGowen (1969), utihzando-os como guias estratigráficos e como marcadores da geometria, em superfície, das grandes estruturas regionais.

UNIDADES DEPOSICIONAIS E LITOESTRATIGRÁFICAS A distribuição das unidades mapeadas, segundo Dominguez \& Rocha (1989) e Rocha (1991), está mostrada no mapa da figura 2.0 embasamento é formado pelo predomínio de uma seqüência supracrustal (Complexo Licínio de Almeida), constituída por gnaisses bandados, quartzitos, formação ferromanganesífera, mármores, rochas cálcio-silicáticas, metachert e anfibolitos. E comum encontrar-se intercaladas ou associadas aos gnaisses bandados massas de corpos granítico-gnáissicos e graníticos isotrópicos, com dimensões variadas, apresentando, algumas vezes, evidências de intrusão (Rocha 1991). Os gnaisses bandados são considerados como sendo de idade proterozóica inferior/arqueana, Jardim de Sá (1984) apresenta uma isócrona $\mathrm{Rb}$-Sr de 1,75 Ga para os granitos de Lagoa Real intrudidos nestes gnaisses. Segundo esse autor, é provável que parte importante das intrusões graníticas da regiấo esteja relacionada com a instalação da Bacia Sedimentar do Espinhaço, a qual teria provocado também a extrusão das rochas vulcânicas félsicas conhecidas na base do Supergrupo Espinhaço.

MAPA dE SITUACĀo

MAPA DE LOCALIZACĀO

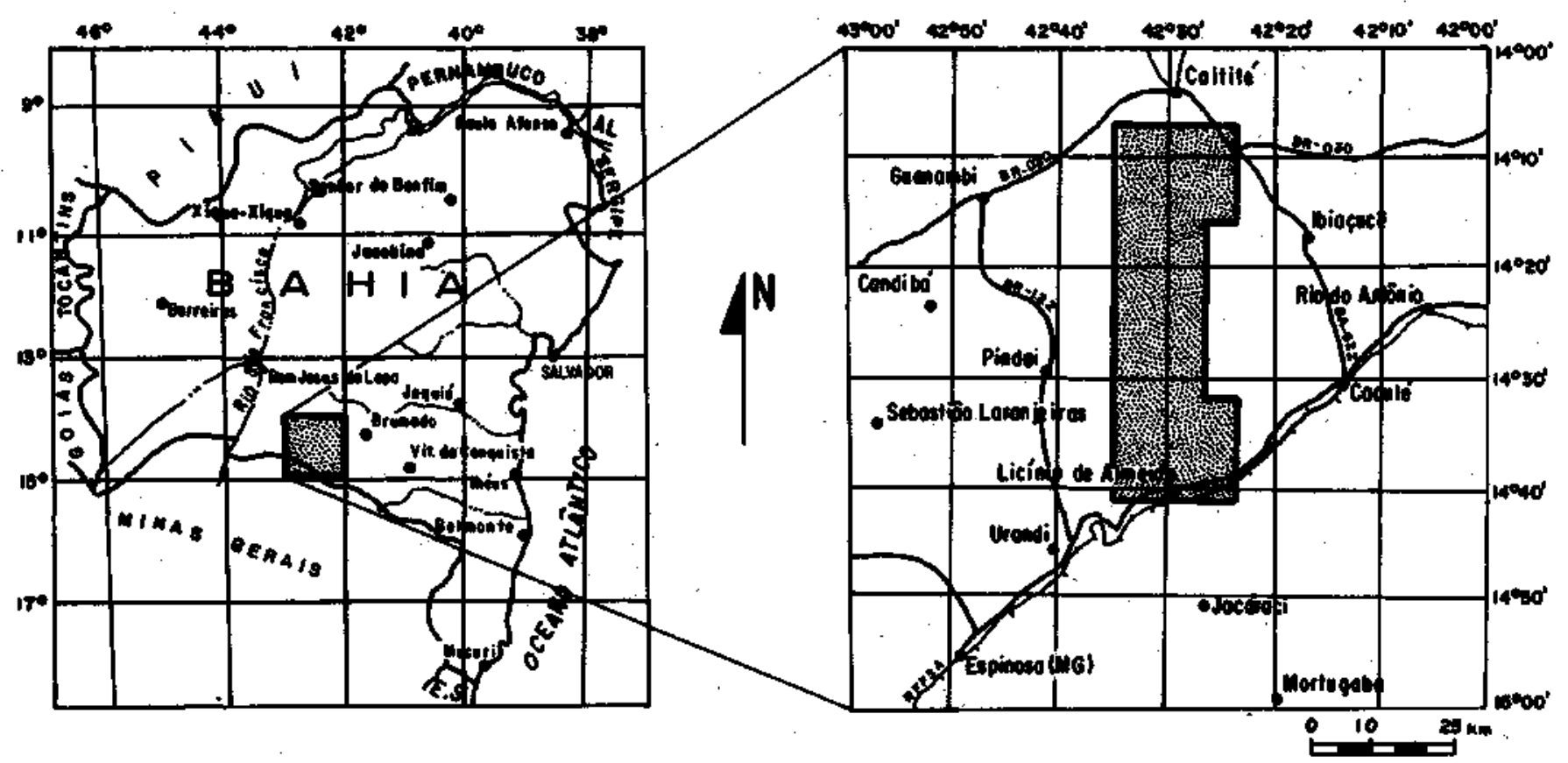

Figura I-Mapas de situagäo e localização da Grea extudada

Figure 1 - Locetion map of the studied ares. 
Uma importante discordância separa as rochas do Complexo Licínio de Almeida e as rochas sedimentares do Espinhaço. Esta discordância seria de caráter erosivo, metamórfico e estrutural, já que as rochas do embasamento apresentam, evidências de terem sido submetidas a um maior número de fases de deformação e de terem sofrido um metamorfismo mais elevado, chegando à fácies de anfibolito médio a alto em alguns locais (Jardim de Sá 1984).

Utilizando o conceito de sistemas depositionais, Dominguez \& Rocha (1989) subdividiram as rochas do Espinhaço de acordo com a figura 3. A aplicação desse método revelou que o Espinhaço Setentrional é constituído por duas seqüências deposicionais: Seqüência Deposicional Borda Leste e Seqüência Deposicional Espinhaço. Segundo os citados autores, a Seqüência Deposicional Borda Leste ocupa a posição basal e compreende um único sistema deposicional (Sistema Deposicional Baixão), constituído por quartzitos e filitos interestratificados que passam em direção ao topo para formações ferromanganesíferas. Esse conjunto de rochas é interpretado como tendo sido depositado em um ambiente plataformal raso, sujeito à ação de ondas de tempestades.

A Seqüência Deposicional Espinhaço é constituída, em ordem estratigráfica ascendente, por três sistemas deposicionais: Salto, Telheiro e Gentio. O Sistema Deposicional Salto é constituído por quartzitos sericíticos, ricos em laminação paralela, e estratificação cruzada de grande porte, com textura fina a média, bem silicificados e localmente conglomeráticos na porção basal. Na base do sistema predominam, portanto, sedimentos depositados em sistemas fluviais entrelaçados, com canais bastante rasos. O restante da sedimentação é essencialmente de caráter eólico.

O Sistema Deposicional Telheiro é constituído por quartzitos médios a finos, sericíticos, localmente avermelhados, apresentando intercalações centimétricas de filitos cinzas a avermelhados. As estruturas sedimentares dominantes sugerem que o Sistema Telheiro teria se acumulado na zona litorânea, mais precisamente na ante-praia exposta continuamente a ação de ondas de tempo bom e de tempestades com correntes fluindo paralelamente à linha de costa.

O Sistema Deposicional Gentio é constituído essencialmente por filitos cinza com intercalações de quartzitos médios a grossos, próximas ao topo. A origem do Sistema Gentio, em virtude das relações faciológicas e estruturas sedimentares, é de ambiente marinho profundo, abaixo da base de ondas de tempestades com progradação de lobos turbidíticos (Dominguez \& Rocha 1989).

ANÁLISE ESTRUTURAL A área estudada possui padrão estrutural complexo; A variação e obliteração das atitudes primárias e o surgimento de novos elementos tectonometamórficos afetando os mais antigos, obrigaram a elaboração de um modelo polifásico, construído a partir de critérios que permitiram analisar o conjunto de dados confuso e heterogêneo encontrados no campo, em partes relativamente mais simples e homogêneas. Procurou-se valorizar, primeiramente, as informações de caráter regional que fossem penetrativas e que estivessem refletidas no mapa geológico da figura 4. O mapa mostra que as atitudes primárias da cobertura sedimentar, principalmente aquelas indicadas para os estratos da Seqüência Deposicional Espinhaço, estão invertidas, mergulhando predominantemente para leste, com variações no sentido longitudinal. Esses estratos apresentam-se, em alguns locais, com dobras apertadas de eixo N-S e com dobras abertas de eixo E-W. Evidências de inversões de atitudes são encontradas com freqüência e indicam uma inversão regional importante.

A seguir serão analisadas as estruturas encontradas nas coberturas sedimentares e no embasamento.

Elementos estruturais Três conjuntos de estruturas são encontrados na área estudada:
1. dobras isoclinais apertadas com eixo N-S, clivagem ardosiana, lineação de interseção, cisalhamento, lineação de estiramento e de crescimento mineral;

2. dobras assimétricas de eixo NNE, clivagem de crenulação, lineação de mini-ondulação, cisalhamento;

3. dobras abertas com eixo E-W.

Os elementos de cada um dos conjuntos estão geneticamente relacionados e são resultantes de pulsos de deformação seqüenciados, já que as estruturas mais novas superpõem ou obliteram total ou parcialmente as mais velhas, gerando, por vezes, novos elementos tectônicos.

Dobras isoclinais Os dobramentos apertados, com tendência a isoclinais (similares), possuem encurtamento de aproximadamente 60-70\% (Hobbs et al. 1976). Apresentam geralmente fechamentos angulares e vergência para oeste, invertendo camadas em um dos seus limbos. São encontrados com diferentes comprimentos de ondas, desde centimétricos até centenas de metros, configurando dobras com os padrões $\mathrm{S}$, $\mathrm{Z}$ e $\mathrm{M}$ de n-ordem. Os planos axiais possuem direções variando predominantemente em torno da N-S e mergulhos com cerca de 45E. Menos freqüentemente, observam-se em algumas faixas planos axiais verticais ou com mergulhos para oeste. Os eixos possuem caimentos variando entre $0^{\circ}$ e $30^{\circ}$ para norte ou sul.

As dobras isoclinais geram uma clivagem ardosiana $\left(\mathrm{S}_{1}\right)$ formada pela orientação e (re)cristalização de minerais (quartzo, muscovita, clorita, óxidos) semiparalela à estratificação primária. Á interseção desta superfície com a clivagem ardosiana evidencia uma lineação $\left(\mathrm{L}_{1}\right)$, paralela ao eixo, que, em alguns casos, mostra também estiramento de cristais (principalmente quartzo).

Evidências deste dobramento, regionalmente, podem ser observadas no embasamento pela repetição da formação ferromanganesífera. Na cobertura sedimentar, na altura do paralelo $14^{\circ} 30^{\prime}$, pelo fechamento (chameira) da litofácies $\mathrm{T}_{1}$ do Sistema Deposicional Telheiro (vide Figs. 2 e 4).

Apesar do dobramento isoclinal possuir estilo apertado, as estruturas sedimentares primárias da cobertura estão bem preservadas e podem ser encontradas com facilidade. Nota-se, entretanto, que estas estruturas estão algo achatadas em virtude da compressão a que foram submetidas. De qualquer forma, a preservação das estruturas primárias é um bom indício de que não houve transposições de estratos na maioria dos casos. Apenas em algumas faixas, onde o strain foi mais intenso, é que as estruturas sedimentares foram destruídas.

Dobras assimétricas Estas dobras são mais freqüentes no domínio da cobertura sedimentar, sendo muito comum a sul da cidade de Licínio de Almeida na Mina de Pedra Preta. Possui estilo assimétrico, vergência para leste, comprimento de onda variável, normalmente com anticlinais bem mais abertos que os sincfinais. Estas dobras geram nitidamente uma clivagem de crenulação de plano axial $\left(\mathrm{S}_{2}\right)$, apresentando quase sempre direções NNE e NNW e mergulhos variando de 40 a $80^{\circ}$ para os quadrantes NW ou SW, com mergulhos mais fortes no embasamento. Neste domínio, a crenulação é rara, não sendo notada nas rochas quartzo-feldspáticas. No domínio da cobertura, a crenulação varia de intensidade. Em alguns locais é tão intensa que mascara quase que completamente a clivagem ardosiana precedente. Já, em outros, é de difícil percepção. Como a clivagem de crenulação $\left(\mathrm{S}_{2}\right)$ afeta tanto a estratificação primária como a clivagem ardosiana $\left(\mathrm{S}_{1}\right)$, ela é posterior a fase isoclinal.

As dobras assimétricas não geram lineações minerais visíveis mesoscopicamente, apenas ondulações, resultantes do eixo da crenulação, são encontradas. Esta lineação $\left(\mathrm{L}_{2}\right)$ possui direção variável em tomo da N-S, sendo mais frequente a direção N30E20. 
Regionalmente, é possível observar a nucleação da dobra assimétrica a norte de Brejinho das Ametistas, a SW do lugarejo de Santa Luzia. Neste local, as atitudes e a geometria da litofácies $\mathrm{T}_{1}$ do Sistema Deposicional Telheiro "marcam" a charneira de um anticlinal aberto, a qual pode ser visualizada em fotografias aéreas e nos mapas das figuras 2 e 4 . Além desta evidência sugestiva, o sinclinal relativamente fechado, constatado no embasamento a partir das atitudes (Figs. 4 e 7), redobra

\section{CONVENÇŌES}

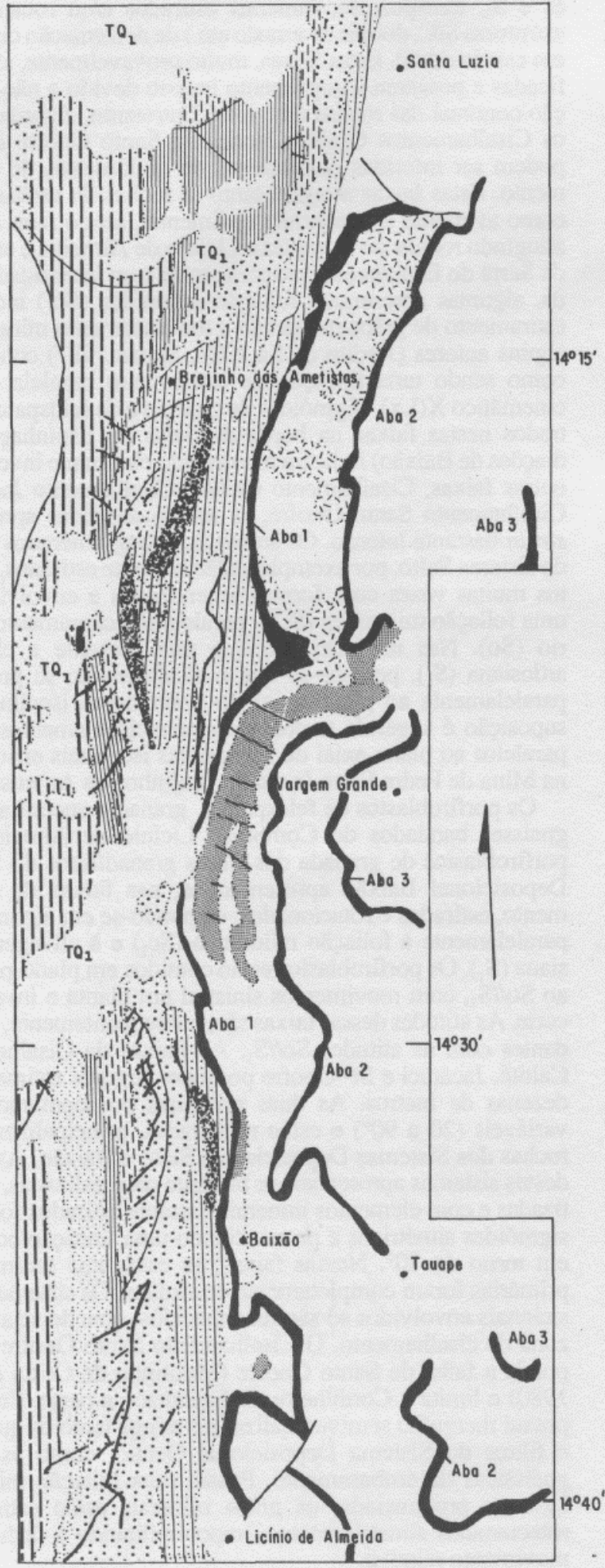

\section{COBERTURA SEDIMENTAR}

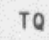

Tercio-quoternário

SEQÜÊNCIA DEPOSICIONAL ESPINHAÇO

SISTEMA DEPOSICIONAL GENTIO

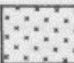

Litotácies 62 (quartzitos)

IIII Litofócies 61 (filitos)

SISTEMA DEPOSICIONAL TELHEIRO

Litofócies $T_{1}$ (quartzitos médios com estratificoçōes

cruzodos acanolados, espinho de peixe)

Litofócies T2 (quartzitos finos com presença de laminoçāo plano-paralela, marcos onduladas )

Litofócies $T 1, T 2$ e T 3 (quartzitos finos, médios, filitos. Presenço de estratificacōes cruzados acanaladas, espinho de peixe, marcos ondulados, "hummocky".)

Telheiro indefinido (filitos granotíferos com intercolaçâo de quartzitos finos :

\section{SISTEMA DEPOSICIONAL SALTO}

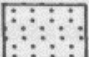

Litofócies S1 e S2 (quartzitos finos a médios, con glomerados na base. Presenço de estratificaçōes cru zadas acanalados, cruzadas de grande porte o laminaçäo plano-poralela )

SEQUEENCIA DEPOSICIONAL BORDA LESTE SISTEMA DEPOSICIONAL BAIXĀO

Litofócies B2 (formaçāo ferromanganesıfera)

Litofócies B 1 (filitos granatiferos e quartzitos. Presenço de laminaçōo plano-paralela, aleitamemto gra dacional e laminaçōo cruzada)

\section{EMBASAMENTO}

Granitóides (gnoisses finamente foliodos, näo bandodos )

\section{COMPLEXO LICÍNIO DE ALMEIDA}

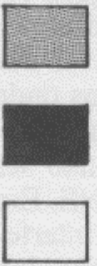

Quartzitos (textura fina o médio com grōos estirados)

Unidade Tauape (formaçāo ferromanganesitera e rochas associados)

Gnaisses bandados (granitóides em menor proporçōo)

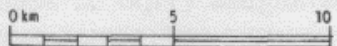

Figura 2 - Distribuição das unidades deposicionais e litoestratigráficas na área trabalhada

Figure 2 - Distribution of depositional and lithostratigraphical units through the surveyed area 


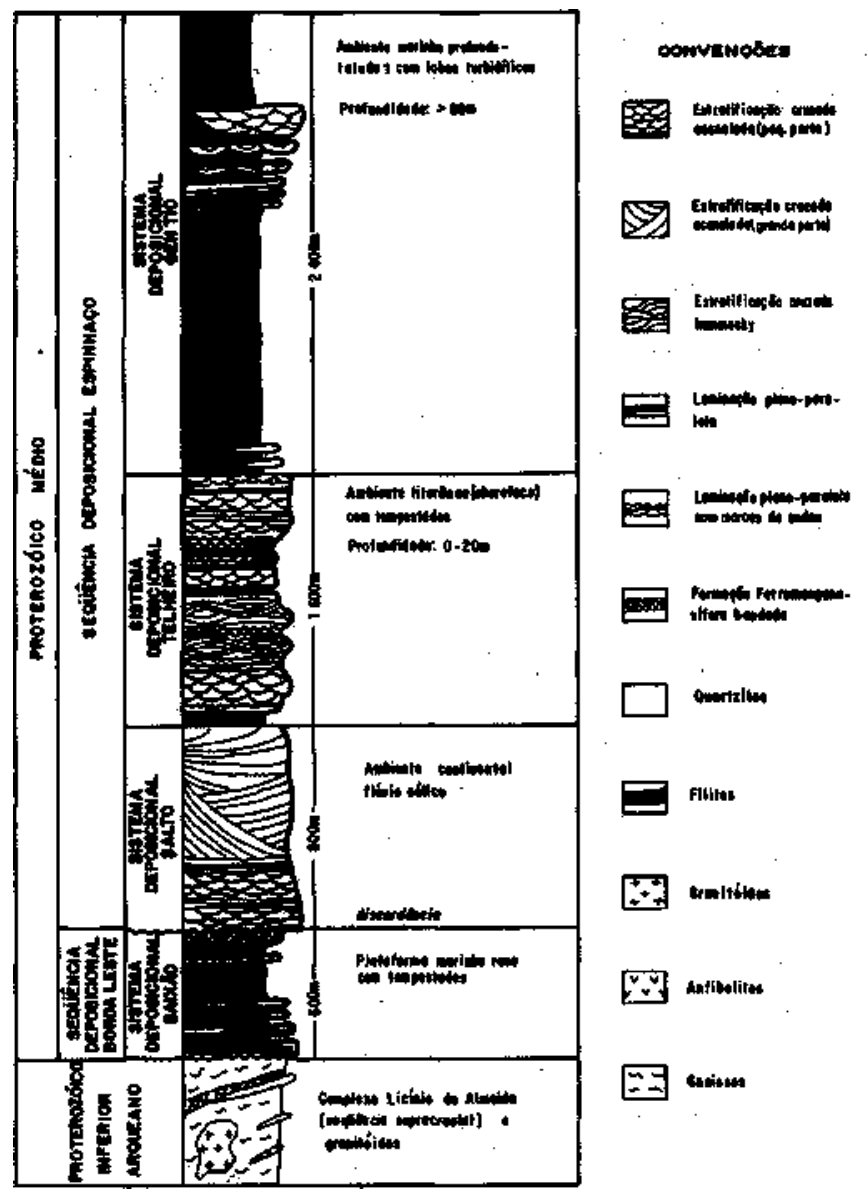

Figura 3 - Coluna estratigráfica esquemática da região estudada, mostrando o embasamento e os principais sistemas deposicionais

Figure 3 - Schematical stratígraphical column of the investigated region, showing the basement and main depositional systems

a fase isoclinal anterior e, provavelmente, complementa o anticlinal aberto da dobra assimétrica.

O dobramento assimétrico, atuando em camadas já dobradas isoclinalmente, provoca variações nos elementos gerados anteriormente $\left(\mathrm{S}_{\mathrm{t}} \mathrm{e} \mathrm{L}_{\mathrm{t}}\right)$ e acentua a inversão de camadas provocada pela fase isoclinal em algumas regiões. A norte de Brejinho das Ametístas, a nucleação da dobra assimétrica, descrita anteriormente, coloca as camadas praticamente de "topo para baixo"

Dobras desarmônicas Este estilo é melhor observado nos gnaisses do embasamento.«São dobras geralmente abertas, apresentando, porém, um apertamento brusco em alguns locais. Este comportamento não-uniforme sugere uma desarmonia decorrente, provavelmente, da plasticidade variável das rochas quartzo-feldspáticas do embasamento. Nas áreas onde são observados os minidòbramentos, percebe-se que esta deformação não gerou elementos planares ou lineares, a não ser eixos com atitudes em torno de 25 a 30 " para ESE e ENE. Em alguns locais, é facilmente observado que estas dobras interferem com as dobras isoclinais anteriores, formando figuras algo semelhantes com bumerangues (Tipo 2, segundo Ramsay 1967). Nas rochas da cobertura sedimentar, esta fase provoca ondulações regionais associada a uma clivagem de fratura, não-penetrativa em toda a região, que está, por vezes, preenchida por veios de quartzo. As dobras desarmônicas são, seguramente, pós-Espinhaço, já que redobram a fase isoclinal. Porém, não foi possível constatar a relação temporal desta fase com a fase assimétrica descrita anteriormente.

Zonas de cisalhamento dúctil É comum encontrar-se na área estudada faixas com dimensões variadas, normalmente com larguras de até dezenas de metros, contendo indicativos (foliação anastomosada, aumento da intensidade das foliações $\mathrm{S}_{1}$ e $\mathrm{S}_{2}$, transposição, minerais estirados e/ou rotacionados, estruturas $\mathrm{S} / \mathrm{C}$, dobras de arrasto etc.) de deformação cisalhante em estado dúctil. Estas faixas, muito provavelmente, são ramificadas e possuem comprimento incerto devido a não-exposição contínua das rochas atingidas. Entretanto, algumas, conto os Cisalhamentos Caetité, Jacaraci e Santo Onofre (Fig. 5), podem ser inferidas por dezenas de quilômetros de comprimento. Estas faixas atingem tanto as rochas do embasamento como as rochas dá cobertura sedimentar, sendo mais comuns atingindo rochas do Complexo Licínio de Almeida e as bordas da Serra do Espinhaço. Possuem strain com intensidade varia$\mathrm{da}$, algumas apresentam foliação milonítica $\left(\mathrm{Sc}_{1}\right)$ incipiente, estiramento de grãos moderado e um lineamento mineral, que alguns autores (Jardim de Sá 1984, Souza 1987) consideram como sendo uma lineação de estiramento paralela ao eixo cinemático X(Lx). Sigmóides de quartzo e de feldspato encontrados nestas faixas na borda da Serra do Espinhaço (imediações de Baixão) indicam movimento cisalhante inverso. Em outras faixas, Cisalhamento Caitité, Cisalhamento Jacaraci e Cisalhamento Santo Onofre, as rochas atingidas apresentam strain bastante intenso. Os seixos dos conglomerados da base do sistema Salto, por exemplo, estão bastante estirados, dispostos muitas vezes com formas amendoadas e envolvidos por uma foliação milonítica (Scl), paralela ao acamamento primário (Só). Nas unidades em que está presente a clivagem ardosiana (S,), percebe-se que o cisalhamento se processou paralelamente ao plano axial do dobramento isoclinal. Esta suposição é sugerida também por minicisalhamentos rúpteis paralelos ao plano axial de minidobras isoclinais encontradas na Mina de Pedra Ferro (a sul de Brejinho das Ametistas).

Os porfiroblastos de feldspato e granada encontrados nos gnaisses bandados do Complexo Licínio de Almeida e os porfiroblastos (te granada dos filitos granadíferos do Sistema Deposicional Baixão apresentam-se, nas faixas de cisalhamento, estirados e rotacionados, dispondo-se em alguns locais paralelamente à foliação milonítica $(\mathrm{Sc}$, ) e à clivagem ardosiana $(\mathrm{S}$,$) . Os porflroblastos estão contidos em plano-paralelos$ ao SQ//SI, com movimentos sinistrai em planta e inverso em corte. As atitudes dessas faixas são, conseqüentemente, concordantes com as atitudes So//S $\mathrm{S}_{1}$. As Faixas de Cisalhamentos Caitité, Jacaraci e $\mathrm{St}^{-}$Onofre possuem larguras estimadas em dezenas de metros. As duas primeiras possuem mergulhos variáveis $\left(20\right.$ a $\left.90^{\circ}\right)$ e estão registradas, principalmente, nas rochas dos Sistemas Deposicionais Salto e Baixão. As rochas destes sistemas apresentam-se bastante recristalizadas, milonitizadas e com elementos minerais bastante estirados formando sigmóides simétricos e pronunciando uma lineação com rake em tomo de $70^{\circ}$. Nessas faixas, as estruturas sedimentares primárias foram completamente destruídas. Os sistemas deposicionais envolvidos só são reconhecidos quando se afasta da zona de cisalhamento. O Cisalhamento Santo Onofre corresponde a falha de Santo Onofre (Moutinho da Costa \& Silva 1980) e limita a Cordilheira do Espinhaço a oeste. Esta faixa possui mergulho semiverticalizado e atinge tanto os quartzitos e filitos do Sistema Deposicional Qentio, como as rochas gnáissicas do embasamento. Possui uma foliação milonítica bastante pronunciada, os grãos minerais estẩo estirados e rotacionados simetricamente, impossibilitando a dedução do movimento relativo.

MODELO POLIFÁSICO Os dados apresentados nos itens anteriores sugerem que a área trabalhada esteve sujeita a episó dios sucessivos de deformação. Tentar explicar os fatos 


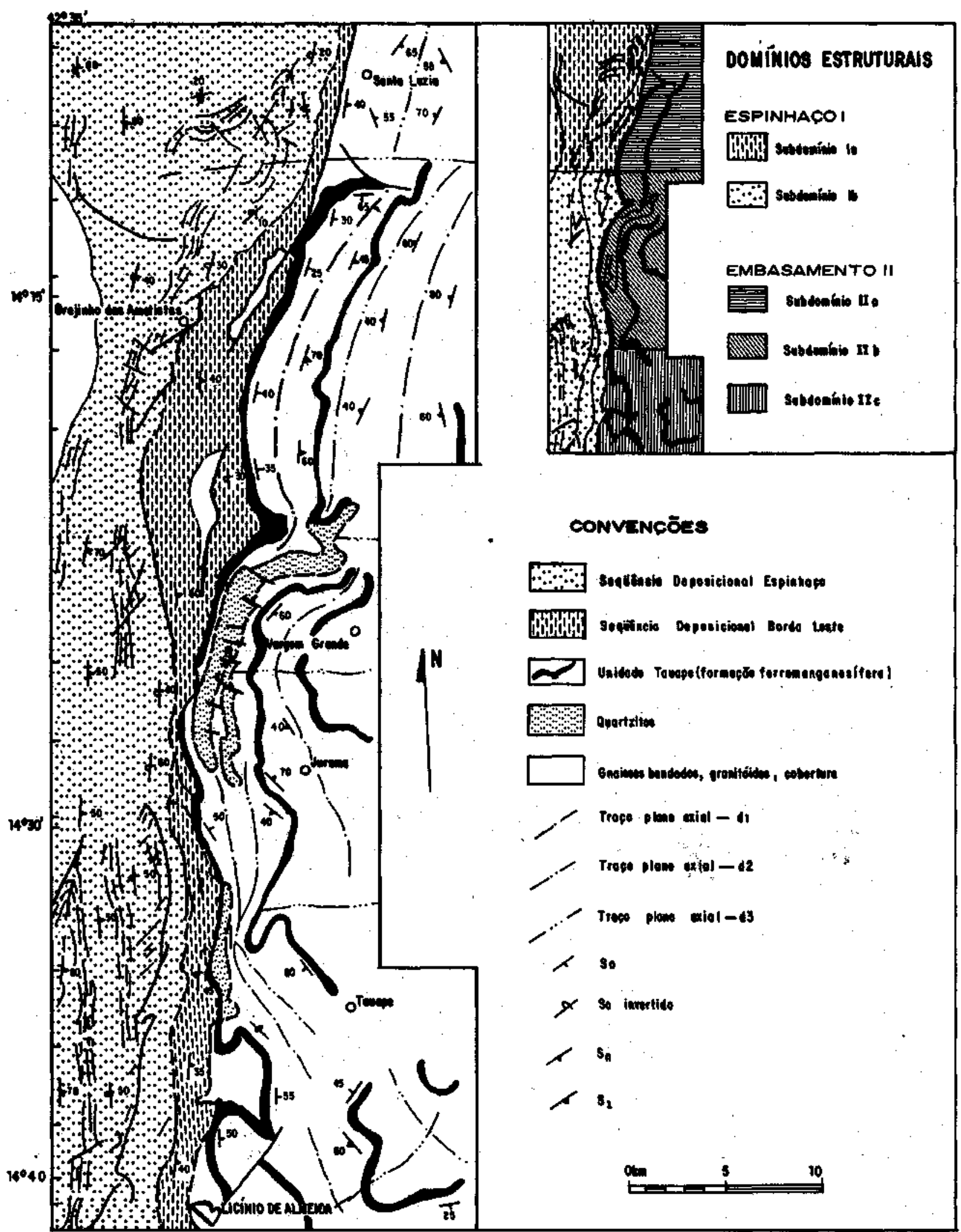

Figura 4 - Mapa geológico estrutural simplificado, mostrando os domínios e os principais elementos estruturais Figure 4 - Simplified structural geological map showing the domains and the principal structural elements 

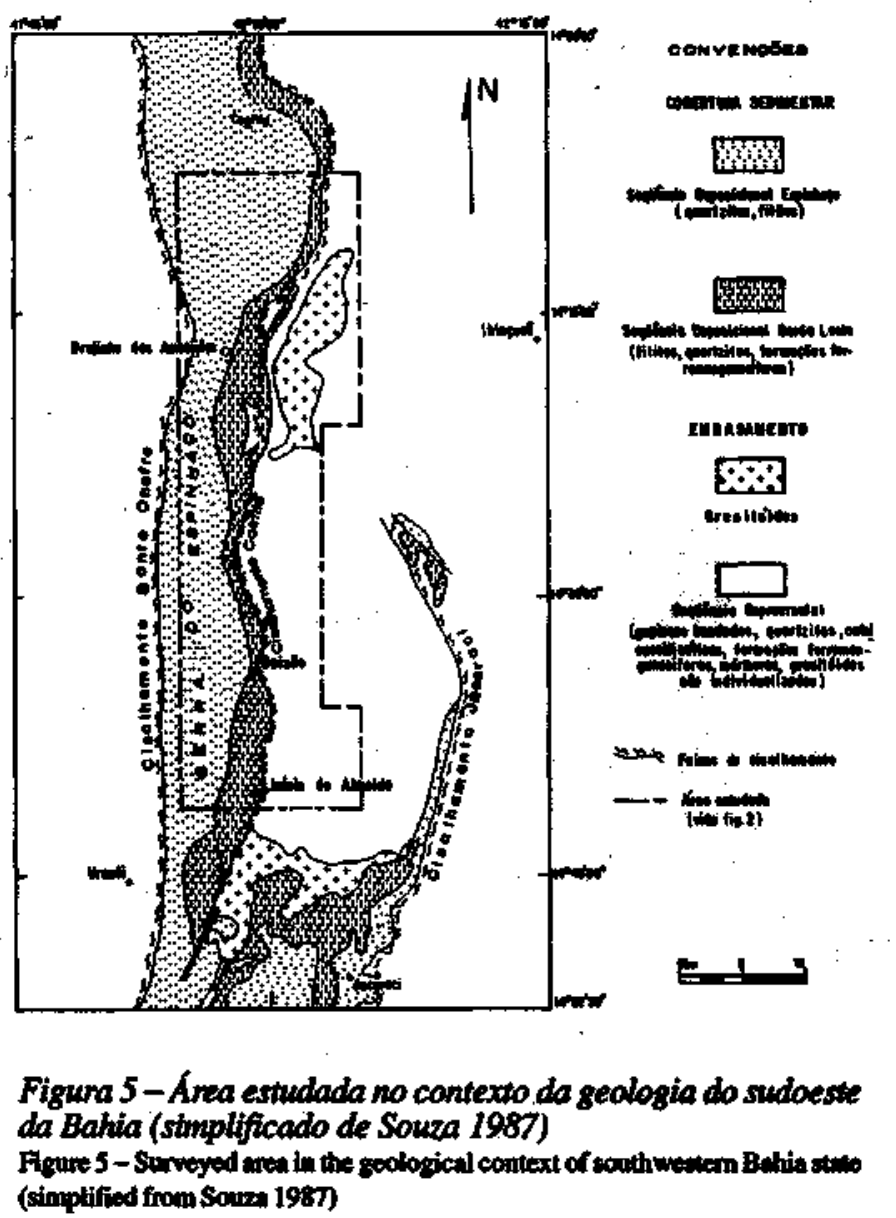

encontrados a partir de um único evento ou fase, mesmo considerando uma deformação progressiva, é uma tarefa bem complicada. Um modelo monofásico não explicaria satisfatoriamente as feições encontradas, tais como: crenulação afetando uma foliação pretérita, rotação de minerais pós-tectônicos em zonas de cisalhamento, fechamentos de dobras no sentido N-S e E-W, redobramentos, camadas com atitudes N-S e E-W, variação significativa dos elementos lineares e planares de origem tectono-metamórfíca. Em vista disto, propomos um modelo polifásico como tentativa ao entendimento do arcabouço estrutural da área. A partir dos elementos estruturais descritos anteriormente, pode-se supor a existência de, pêlo menos, dois períodos tectônicos importantes: Pré-Espinhaço e Espinhaço.

Tectônica Pré-Espinhaço Entende-se por tectônica PréEspinhaço aquela que atingiu somente o embasamento, sem afetar as rochas das Seqüências Deposiciohais Espinhaço e Borda Leste. Esta deformação processou-se em pelo menos uma fase (Dn) que originou o bandamento metamórfico $(\mathrm{Sn})$ que caracteriza os gnaisses bandados do Complexo Licínio de Almeida. Não foram observadas, na área estudada, dobras equivalentes a esta fase de deformação. Entretanto, Jardim de Sá (1984) admite que dobras intrafoliais recumbentes (D:n), encontradas a leste de Licínio te Almeida, estejam associadas a esta fase. Isto implica que o dobramento isoclinal recumbente paralelizou o bandamento metamórfico (Sn) com o acamamentopriniário das litologias supracrustais do embasamento.

É muito provável que a defonnação Dn tenha sido processada no Ciclo Transamazônico ou/em ciclos anterioresemcondições metamórfícas da fácies anfibolito médio a alto, provocando migmatização e/ou granulitização em alguns locais (Jardim de Sá 1984).
Tectônica Espinhaço Admite-se que três fases (ou subfases) de deformação atingiram conjuntamente a cobertura sedimentar e o embasamento: $\left(\mathrm{D}_{1}\right.$ dobramento isoclinal $\left(\mathrm{D}_{1}\right) /$ cisalhamento $\left(\mathrm{c}_{1}\right) ;\left(\mathrm{D}_{2}\right)$ dobramento assimétrico $\left(\mathrm{D}_{2}\right) /$ cisalhamento $\left(\mathrm{c}_{2}\right)$; e $\left(\mathrm{D}_{3}\right)$ dobramento desarmônico $\left(\mathrm{D}_{3}\right)$.

Como discutido anteriormente, o dobramento isoclinal (D,) atua sobre o acamamento primário (Só) gerando uma clivagem ardosiana $\left(\mathrm{S}_{\mathrm{t}}\right)$ e lineações de interseção e de estiramento mineral $\left(\mathrm{L}_{1}\right)$. $\mathrm{O}$ dobramento assimétrico $\left(\mathrm{D}_{2}\right.$ atua sobre $\mathrm{O}$ acamamento primário (So) e a clivagem ardosiana $\left(\mathrm{S}_{1}\right)$ gerando uma clivagem de crenulação $\left(\mathrm{S}_{2}\right)$ e uma lineação de interseção $\left(\mathrm{L}_{2}\right), \mathrm{O}$ dobramento desarmônico $\left(\mathrm{D}_{3}\right)$ não gera elementos planares ou lineares, mas provoca variação das atitudes dos elementos das fases anteriores.

Procurando entender o efeito que as fases de dobramentos provocaram, a área estudada foi dividida segundo os domínios da figura 4.0 domínio I engloba as litologias das Seqüências Deposicionais Espinhaço e Borda Leste e possui atitudes de Só e SI paralelizadas, variando entre 10 e $80^{\circ}$ (dip), sendo a de maior freqüência N10E 40SE (Fig. 6). Este paralelismo é provocado pelo dobramento isoclinal $\left(\mathrm{D}_{1}\right)$ que possui eixo $\mathrm{B}$ de S4E10. Os subdomüaios Ia e Ib (Fig. 6) mostram que os estratos primários $(\mathrm{So})$ e a clivagem ardosiana $\left(\mathrm{S}_{1}\right)$ paralelizados sofrem inflexão (torção) a norte (domínio Ia). As camadas inclinam-se de direção aproximadamente $24^{\circ}$ para leste, suavizando o mergulho em torno de $16^{\circ}$. Esta torção dos estratos é interpretada como sendo causada pelos dobramentos posteriores ao dobramento isoclinal $\left(\mathrm{D}_{1}\right)$, principalmente pelo dobramento assimétrico $\left(\mathrm{D}_{2}\right)$. A norte de Brejinho das Ametistas, observa-se a nucleação de uma dobra regional assimétrica, cujo traço axial possui direção de aproximadamente N30E.

O domínio II (Fig. 7) possui dados $\mathrm{So} / \mathrm{Sn}$ do embasamento configurando um smclinal com os planos mergulhando em tomo de N22E 40SE e N44W 40SW. Esta estrutura é interpretada como sendo um sinclinal curto da dobra assimétrica $\left(\mathrm{D}_{2}\right.$ que possui traço de plano-axial ondulado, como é visto no mapa da figura 5 .

EVOLUÇÃO TECTONO-METAMÓRFÍCA A evolução tectono-metamórfica proposta está sintetizada no quadro da tabela 1. Segundo esse quadro, as seqüências deposicionais do Proterozóico Médio (Seqüências Deposicionais Borda Leste e Espinhaço) instalaram-se em terrenos arqueanos/proterozóicos inferiores (pré-Borda Leste) já deformados, em pelo menos uma fase (tectonismo pré-Espinhaço), durante a qual originou-se o bandamento gnáissico ( $\mathrm{Sn})$, sob condições metamórficas do fácies anfíbolito médio a alto. Três fases de dobramentos atingiram as seqüências deposicionais e o embasamento. A presença de quatro fases no embasamento e três na cobertura implica, portanto, uma discordância estrutural importante entre estas duas macrounidades. A partir da análise estrutural, é possível supor que a discordância estrutural é de baixo ângulo, em tomo de 10 a $15^{\circ}$. A discordância angular é bastante sutil, devido a tendência à paralelização de planos pretéritos, imposta pela fase isoclinal $\left(\mathrm{D}_{1}\right)$. A rase $\mathrm{d}_{1}$, apertada e com vergência para oeste, representa uma deformação não coaxial, cujos elementos foram apertados, estirados e rotacionados para oeste, implicando um transporte de massa considerável nessa direção. A depender da profundidade, faixas de cisalhamento dúcteis, com deslocamentos contendo componentes sinistrai/inverso, foram formadas provocando movimentos de blocos diferenciados. Restos de litologias da Seqüência Deposicional Espinhaço, poupados pela erosão, encontrados no embasamento (Fig. 5) são interpretados como sendo cunhas tectônicas resultantes desses movimentos que, em Unhas gerais, podem ser considerados como de acavalamento. É muito provável, como já foi demonstrado por outros autores (Moutinho da Costa \& Inda 1982), que os restos da sedimentação encontrados no embasamento impliquem que a sedimentação do Espinhaço e da Chapada Diamantina esteja 


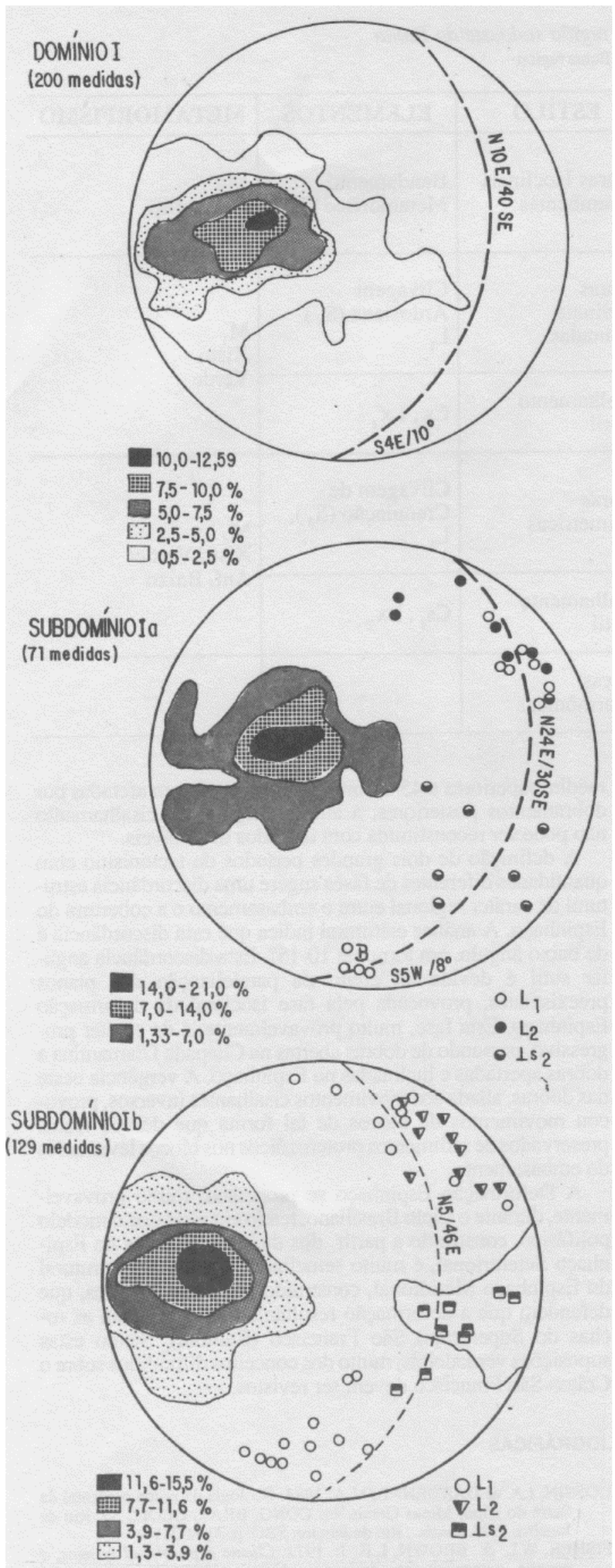

Figura 6-Diagramas de freqüencia (hemisfério inferior) para atitudes das camadas nos domínios e subdomínios do Espinhaço Figure 6 - Frequency diagrams (lower hemisphere) for bed attitudes in the Espinhaço domains and subdomains

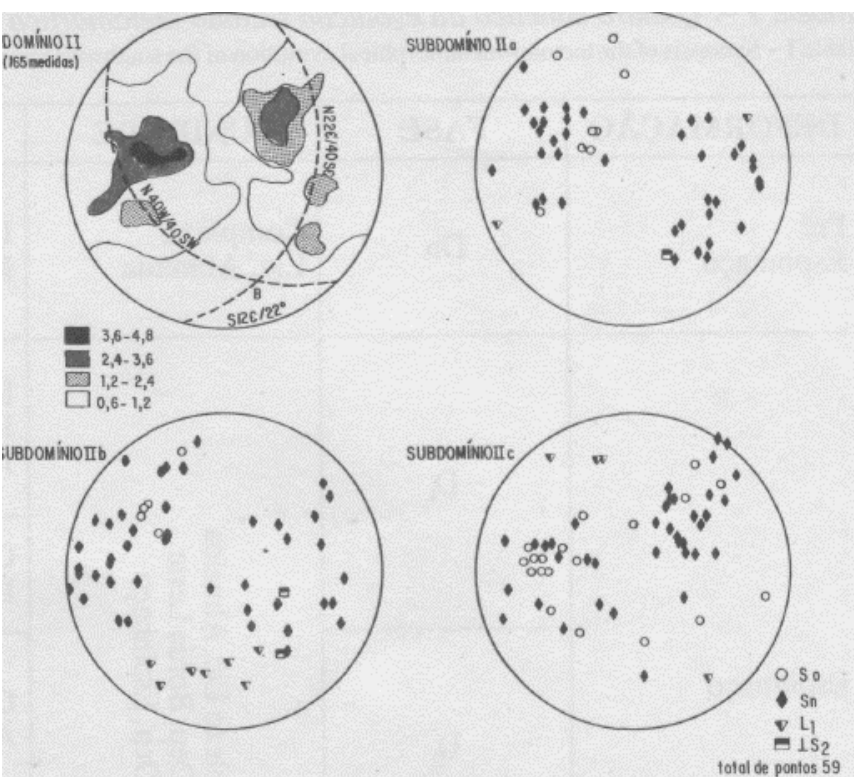

Figura 7 - Diagramas de freqüência (hemisfério inferior) para atitudes de camadas nos domínios e subdomínios do embasamento

Figure 7 - Frequency diagrams (lower hemisphere) for bed attitudes in the basement domains and subdomains

relacionada, não só cronofaciologicamente, mas também espacialmente.

Os principais elementos gerados na fase 1 , dobras isoclinais associadas a cisalhamentos, constituem as estruturas mais elucidativas para a compreensão da geologia do Proterozóico na área em questão. Elas foram responsáveis pela inversão estratigráfica com inversão de camadas (o Espinhaço no sudoeste da Bahia está praticamente todo invertido) e pelo transporte de massa, forte em direção a oeste (movimento oblíquo sinistrai/inverso). É provável que esta deformação tenha sido progressiva, passando desde dobras abertas na Chapada Diamantina para dobras apertadas no Cinturão do Espinhaço, ou que a progressão tenha se dado a partir do Vale do Paramirim, gerando estruturas com vergência oposta (como rmтрор up), com movimento de massa mais intenso cavalgando para oeste. As outras fases $F_{2}$ e $F_{3}$ imprimem acomodaçỗes locais importantes para a compreensão do arcabouço estrutural, entretanto, é preciso dimensionar, com trabalhos em outras áreas, o alcance regional destas fases. Algumas faixas de cisalhamento, por exemplo, não podem ser consideradas simplesmente como uma manifestação tardia da deformação isoclinal. Elas afetam rochas anteriormente metamorfizadas e com movimento de blocos em desacordo com o movimento cisalhante da primeira fase $\left(\mathrm{F}_{1}\right)$, normalmente possuem movimentos de massa menos intensos e com direção para leste. Por outro lado, os porfiroblastos, nitidamente pós-tectônicos à foliação $S_{1}$ e sintarditectônicos à foliação $\mathrm{S}_{2}$, estão estirados e relacionados por faixas de cisalhamento. A foliação $\mathrm{S}_{2}$, nestas faixas, é intensificada, destruindo completamente a foliação pretérita $\left(\mathrm{S}_{1}\right)$. Essas faixas podem representar a reativação de faixas mais antigas ou uma nova fase. Mesmo considerando que os fatos ainda não são muito esclarecedores, optamos por definir duas fases de cisalhamento C, e Q, como mostra o quadro da tabela 1. A tectônica que atingiu as rochas do Espinhaço Setentrional pode ter sido impressa durante o Ciclo Espinhaço $(1,35 \mathrm{Ga})$ ou mesmo durante o Ciclo Brasiliano ( $0,7 \mathrm{Ga})$, já que no Espinhaço Meridional, segundo alguns autores (Dossin \& Dardenne 1984, Uhlein et al. 1986, Kiang et al. 1988), estruturas equivalentes às discutidas neste trabalho, deformam tanto as litologias do Espinhaço quanto às do Grupo Bambuí. 
Tabela 1 - Quadro sintético da evolução tectono-metamórfica da região sudoeste da Bahia Table 1 - Synopsis of the tectono-metamorphical evolution of the southwestern state Bahia region

\begin{tabular}{|c|c|c|c|c|c|}
\hline DEFORMAÇĀO & FASE & · UNIDADE & ESTILO & ELEMENTOS & METAMORFIṠMO \\
\hline $\begin{array}{l}\text { Pre } \\
\text { Espinhaço }\end{array}$ & Dn & $\begin{array}{l}\text { Complexo } \\
\text { Lic. Almeida }\end{array}$ & $\begin{array}{l}\text { Dobras Isoclinais } \\
\text { Recumbentes }\end{array}$ & $\begin{array}{l}\text { Bandamento } \\
\text { Metamorfico (Sn) }\end{array}$ & $\begin{array}{l}\text { Mn } \\
\text { Anfibolito }\end{array}$ \\
\hline \multirow{5}{*}{ Espinhaço } & \multirow[t]{2}{*}{$\mathrm{D}_{\mathbf{1}}$} & \multirow{5}{*}{ 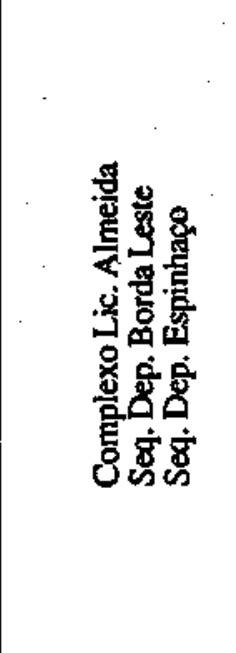 } & $\begin{array}{l}\text { Dobras } \\
\text { Isoclinais } \\
\text { Inclinadas }\end{array}$ & $\begin{array}{l}\text { Clivagem } \\
\text { Ardosiana }\left(S_{1}\right) \\
\mathrm{L}_{1}\end{array}$ & \multirow{2}{*}{$\begin{array}{l}\mathbf{M}_{1} \\
\text { Xisto } \\
\text { Verde }\end{array}$} \\
\hline & & & $\begin{array}{l}\text { Cisalhamento } \\
\text { Ductil }\end{array}$ & $C s_{1}, L x_{1}$ & \\
\hline & \multirow[t]{2}{*}{$\mathbf{D}_{2}$} & & $\begin{array}{l}\text { Dobras } \\
\text { Assimetricas }\end{array}$ & $\begin{array}{l}\text { Clivagem de } \\
\text { Crenulaçăo }\left(\mathrm{S}_{2}\right) \text {, } \\
\mathrm{L}_{3}\end{array}$ & \multirow{2}{*}{$\begin{array}{l}\mathbf{M}_{2} \\
\text { Xisto Verde/ } \\
\text { Anf. Baixo }\end{array}$} \\
\hline & & & $\begin{array}{l}\text { Cisalhamento } \\
\text { Dúctil }\end{array}$ & $\mathrm{Cs}_{2}, \mathrm{Lx}_{2}$ & \\
\hline & $\mathrm{D}_{3}$ & & $\begin{array}{l}\text { Dobras } \\
\text { Desarmônicas }\end{array}$ & - & - \\
\hline
\end{tabular}

CONCLUSÕES A análise estrutural realizada definiu dois importantes períodos de tectonismo: Tectônica Pré-Espinhaço e Tectônica Espinhaço. Durante a tectônica PréEspinhaço, desenvolveu-se, fundamentalmente, o bandamento metamórfico característico dos gnaisses bandados da seqüência supracrustal. Este bandamento representaria planos tectonometamórficos, causados por dobras isoclinais recumbentes, desenvolvidas durante o Arqueano/Proterozóieo Inferior em condições rnetamórficas de médio grau (fácies anfibolito).

Durante a Tectônica Espinhaço, desenvolveram-se três fases de dobramentos sucessivos, com estilos diversos, associadas a faixas de cisalhamentos dúcteis. A primeira fase de dobramento, de estilo isoclinal, foi fundamental no modelamento estrutural da área estudada. Esta fase, responsável pela repetição (mapeável) das camadas mineralizadas de manganês, teria provocado a inversão de camadas, observável em diversos pontos do Espinhaço Setentrional. A inversão de camadas provocou, conseqüentemente, a inversão estratigráfica, fazendo com que as camadas mais antigas se posicionassem estruturalmente por cima das camadas mais novas. Durante a fase tarditectônica ao dobramento isoclinal, desenvolveram-se movimentos cisalhantes inversos, cuja soma de resultados provocou um significativo movimento de massa vindo de leste para oeste. Apesar de alguns autores considerarem estes movimentos como sendo de empurrão, a maioria das atitudes observadas nas faixas de Cisalhamento é variável e os mergulhos são, em média, superiores a $45^{\circ}$. Como estas faixas foram afetadas por dobramentos posteriores, a atitude original do Cisalhamento não pode ser reconstituída com os dados disponíveis.

A definição de dois grandes períodos de tectonismo com quantidades diferentes de fases sugere uma discordância estrutural de caráter regional entre o embasamento e a cobertura do Espinhaço. A análise estrutural indica que esta discordância é de baixo ângulo, em torno de $10-15^{\circ}$. Esta discordância angular sutil é devida ao efeito da paralelização dos planos preexistentes, provocada pela fase isoclinal da deformação Espinhaço. Esta fase, muito provavelmente, é de caráter progressivo, passando de dobras abertas na Chapada Diamantina a dobras apertadas e inclinadas no Espinhaço. A vergência oeste das dobras, aliada aos movimentos cisalhantes inversos, provocou movimentos de blocos de tal forma que deixou restos preservados de sedimentos proterozóicos nos blocos levantados do embasamento.

A Deformação Espinhaço se processou, muito provavelmente, durante o Ciclo Brasiliano, tendo em vista que o modelo polifásico, construído a partir dos dados levantados no Espinhaço Setentrional, é muito semelhante ao modelo estrutural do Espinhaço Meridional, construído por outros autores, que defendem que a deformação resultante afetou também as rochas do Supergrupo São Francisco (Bambuí). Sendo estas suposições verdadeiras, muito dos conceitos difundidos sobre o Cráton São Francisco devem ser revistos.

\section{REFERÊNCIAS BIBLIOGRÁFICAS}

BROWN, L.F, Jr. \& FISHER, W.L. 1977. Seismic-stratigraphic interpretation of depositional systems: examples from Brazilian rift and pull-apart basins. In: PAYTON, V.C.E. ed. Seismic Stratigraphy Applications to Hydrocarbon Exploration. Tulsa, Am. Assoc. Petrol. Geol. p. 213-248. (Memoir 26)

DOMINGUEZ J. M. L. \& ROCHA, G. M. F. 1989. Seqüências deposicionais do Espinhaço Setentrional na região Sudoeste do Estado da Bahia: uma margem continental proterozóica? In: SIMP. GEOL. MINAS GERAIS, 5 e SIMP. GEOL. BRASÍLIA. 1. Belo Horizonte, 1989. Anais... Belo Horizonte, SBG. Boi. 10,293 p.
DOSSIN, LA. \& DARDENNE, M.A. 1984. Geologia da borda ocidental da Serra do Cipó, Minas Gerais. In: CONG. BRAS. GEOL., 33. Rio de Janeiro, 1984. Anais... Rio de Janeiro, SBG. p. 3104-3117.

FISHER, W.L. \& BROWN, L.F., Jr. 1972. Clastic depositional systems, a genetic approach to fades analysis; annotated outline and bibliography. Texas, Univ. Texas/Bur. Econ. Geol. 230 p (Spec. Rept.).

FISHER, W.L.\& McGOWEN,J.H. 1969. Depositional systems in the Wilcox Group (Eocene) of Texas and their relation to ocurrence of oil and gas. Am. Assoc. Petrol. Geol. Bull., 53:30-54.

GARRIDO, I.A.A. 1984. Projeto Tauape. Salvador, SME/CBPM. 62 p. 
HOBBS, B.E.; MEANS, W.D.; WILLIAMS, PE. 1976. An outline ot Structural Geology. Londres, Wiley \& John. 571 p,

INDA H. A.V. \& BARBOSA J.F. 1978. Texto Explicativo para o Mapa Geológico do Estado da Bahia - Escala 1:1.000.000. Salvador, SME/CPM. 137p.

JARDIM DE SÁ, E.F. 1984. Relatório de Consultoria no Âmbito dos Projetos "Mapa Metamórfico da Bahia" e "Caitité". Salvador, SME/CBPM.24p.

KIANG, C.H.; MIRANDA, E.P.; MAGALHÃES, L.; ALKMIN, F.F. 1988. Considerações sobre a evolução tectônica da Bacia do São Francisco. In: CONG. BRAS. GEOL., 35. Belém, 1988. Anais... Belém, SBG. v. 5, p. 2076-2090.

MASCARENHAS, J. F.; PEREIRA, AJ.CL.; GIL C.A.A - NEVES, J.P. DAS; OLIVEIRA, J.E.; SILVA, M.A., F.; MARINHO, M.M. 1979. Geologia da Região Centro (Mental da Bahia. Projetos Bahia $\bullet$ Bahia 11-Sul da Bahia. Relatório Integrado. Brasília, DNPM/CPRM. 128 p. (Série Geologia 11. Seção GeoL Básica 8).

MORAES, L.C. 1980. Projeto Bnmado-Caetité. CPRM/SRS, v. I, 183 p. (Relatório Final).

MOUTINHO DA COSTA, L.A. \& INDA, H.A.V. 1982. $O$ aulacógeno do Espinhaco. Rev. Ciências da Terra, 2:13*18.

MOUTINHO DA COSTA, L.A. \& SILVA, W.G. 1980. Projeto Santo Onofre. Mapeamento Geológico. DNPM/CPRM. 373 p. (Relatório Final).
PORTELA, A.C.P.; MARCHETTO, C.L.; MENEGUESSO, G.; STEIN, J.H.; MOUTINHODACOSTA,L.A.;BATISTA,M.B.;MOSSMANN,R;SILVA, W.G. 1976. Projeto Leste de Tocantins/Oeste do Rio São Francisco; Fase V.S.L. RiodeJaneiro,DNPM/CPRM.300p.(RelatórioFinallA).

RAMSAY, J.G. 1967. Folding and'Fracturing of Rocks. 1 ed. New York, McGrawHul.568p.

ROCHA, G, M. F. 1991. Projeto Instruo Manganesífero do Sudoeste da Bahia. Salvador, SGM. 107 p. (Relatório)

SÁ, J.H.S. 1983. Mapa Metalogenético do Estado da Bahia (Escala 1:1.000.000). Salvador, SME/CPM. 61 p. (Texto Explicativo).

SOUZA, S JL. 1987. Projeto Caetité. Salvador, SME/CBPM. 240 p.

STEIN, J.H.; MOUTINHO DA COSTA, I«A.; BATISTA. M.B.; SILVA, W.G. 1976. Projeto Leste do Tocantins/Oeste do Rio São Francisco: Relatório Final. Fase V. s.l. DNPM/CPRM, v.lb, 275 p.

UHLEIN, A.;DOSSIN,I.A.;CHAVES,M.L.S.C. 1986. Contribuição à geologia estrutural e tectômca das roxas arqueanas e proterozóicas Espinhaco Meridional-MG. In: CONG. BRAS. GEOL. 34. Goiânia, 1986. Anais... Goiânia, SBG. v. 3. p. 1191-1203.

MANUSCRITO A738

Recebido em 12 de maio de 1992 Revisão do autor em 7 de agosto de 1992 Revisão aceita em 25 de setembro de 1992 